\title{
Effects of Aliskiren on blood pressure and the predictive biomarkers for cardiovascular disease in hemodialysis-dependent chronic kidney disease patients with hypertension
}

\author{
Yoshiyuki Morishita $^{1}$, Shiho Hanawa ${ }^{1}$, Junko Chinda ${ }^{1}$, Osamu Iimura ${ }^{2}$, Sadao Tsunematsu ${ }^{3}$ and Eiji Kusano ${ }^{1}$
}

The renin-angiotensin-aldosterone system (RAAS) has pivotal roles in the pathogenesis of hypertension in hemodialysisdependent chronic kidney disease (HDD-CKD) patients. Activated RAAS also increases inflammatory mediators by directly increasing proinflammatory gene expression and by putting oxidative stress on the vascular endothelium. Both hypertension and inflammation are major risk factors for cardiovascular disease (CVD) in HDD-CKD patients. In this study, we assessed the efficacy of a direct renin inhibitor, aliskiren, on blood pressure (BP) and CVD predictive biomarkers, such as brain natriuretic peptide (BNP), high-sensitivity C-reactive protein (hs-CRP) and diacron-reactive oxygen metabolite (d-ROM). A total of 30 hypertensive HDD-CKD patients were assigned to receive aliskiren $(150 \mathrm{mg})$ orally once daily with their existing antihypertensives. After 8 weeks, aliskiren treatments reduced systolic blood pressure (SBP) from $169.0 \pm 20.1$ to $153.7 \pm 19.6 \mathrm{~mm} \mathrm{Hg}(P<0.001)$ and diastolic blood pressure (DBP) from $78.1 \pm 12.0$ to $73.0 \pm 13.6 \mathrm{~mm} \mathrm{Hg}(P=0.048)$. RAAS was suppressed by aliskiren treatment as follows: PRA (from $3.6 \pm 4.0$ to $1.0 \pm 1.5 \mathrm{ng} \mathrm{ml}^{-1} \mathrm{~h}^{-1}(P=0.004)$ ), angiotensin I (from $1704.0 \pm 2580.9$ to $233.7 \pm 181.0 \mathrm{pg} \mathrm{ml}^{-1}(P=0.009)$ ), angiotensin II (from $70.2 \pm 121.5$ to $12.4 \pm 11.5 \mathrm{pg} \mathrm{ml}^{-1}(P=0.022)$ ) and aldosterone (from $107.9 \pm 148.0$ to $73.1 \pm 34.6 \mathrm{pg} \mathrm{ml}^{-1}$ (NS)). The biomarkers for CVD were inhibited by aliskiren: BNP (from $362.5 \pm 262.1$ to $300.0 \pm 232.0 \mathrm{pg} \mathrm{ml}^{-1}(P=0.043)$ ), hS-CRP (from $6.2 \pm 8.1$ to $3.5 \pm 3.7 \mathrm{mgl}^{-1}(P=0.022)$ ) and d-ROM (from $367.0 \pm 89.8$ to $328.3 \pm 70.9$ U.CARR $(P=0.022)$ ). The inhibition levels of biomarkers for CVD by aliskiren did not correlate with the decreased levels of SBP and DBP. These results suggested that aliskiren was effective for BP control and may have cardiovascular protective effects in hypertensive HDD-CKD patients.

Hypertension Research (2011) 34, 308-313; doi:10.1038/hr.2010.238; published online 2 December 2010

Keywords: aliskiren; blood pressure; biomarkers for cardiovascular disease; hemodialysis-dependent chronic kidney disease patients

\section{INTRODUCTION}

Cardiovascular disease (CVD) is the leading cause of morbidity and mortality in hemodialysis-dependent chronic kidney disease (HDDCKD) patients. Hypertension is a major risk factor for CVD. The renin-angiotensin-aldosterone system (RAAS) has pivotal roles in the pathogenesis of hypertension in HDD-CKD patients, although volume overload is considered the most critical factor. ${ }^{1}$ The renin levels of hypertensive HDD-CKD patients were found to be approximately twice as high as those of normal subjects. ${ }^{2}$ Parenchymal renal injury and renovascular disease may cause increased renin secretion in end-stage renal failure. ${ }^{1,2}$ The role of RAAS in hypertensive HDDCKD patients was confirmed by the normalization of blood pressure (BP) by administration of an angiotensin antagonist, saralasin. ${ }^{3}$

Persistent inflammation in uremic conditions has been shown to be an independent predictor of CVD in HDD-CKD patients. ${ }^{4,5}$ Activated RAAS also increased inflammatory mediators by directly increasing proinflammatory gene expression and by putting oxidative stress on vascular endothelium. ${ }^{6}$ Therefore, the blockade of RAAS is important to control BP and suppress inflammation leading to CVD in HDDCKD patients. Although the blockade of RAAS by angiotensin I converting enzyme inhibitors (ACEIs) and angiotensin receptor blockers (ARBs) has been reported to show effects on BP control and to suppress inflammation, ${ }^{7,8}$ it does not completely suppress RAAS, leading to a reactive rise in plasma renin activity (PRA).

Aliskiren, an oral direct renin inhibitor, is effective against essential hypertension by reducing PRA, resulting in more complete suppression of RAAS; ${ }^{9}$ however, little is known about the effects of aliskiren on hypertensive HDD-CKD patients. In this study, we assessed the efficacy of aliskiren on BP and the biomarkers for CVD, such as brain natriuretic peptide (BNP), high-sensitivity C-reactive protein (hs-CRP) and diacron-reactive oxygen metabolite (d-ROM), in hypertensive HDD-CKD patients.

${ }^{1}$ Division of Nephrology, Department of Medicine, Jichi Medical University, Tochigi, Japan; ${ }^{2}$ Kumakura Clinic, Tochigi, Japan and ${ }^{3}$ Yuki Clinic, Ibaragi, Japan Correspondence: Dr Y Morishita, Division of Nephrology, Department of Medicine, Jichi Medical University, 3311-1, Yakushiji, Shimotsuke-city, Tochigi 329-0498, Japan. E-mail: ymori@jichi.ac.jp

Received 2 June 2010; revised 5 August 2010; accepted 30 August 2010; published online 2 December 2010 


\section{METHODS}

This study was performed in accordance with the Declaration of Helsinki and was approved by the ethics committee of Jichi Medical University. Written informed consent was obtained from all patients.

\section{Patients}

HDD-CKD patients with hypertension were enrolled in the study. All patients had oliguria or anuria. Patients were classified as hypertensive when clinic BP was $\geqslant 140 \mathrm{~mm} \mathrm{Hg}$ for systolic BP (SBP) and $\geqslant 90 \mathrm{~mm} \mathrm{Hg}$ for diastolic BP (DBP) before an hemodialysis (HD) session on the last HD day of the week. Exclusion criteria were as follows: age $<20$ years or $>80$ years, type I diabetes mellitus or type II diabetes mellitus with poor glucose control (glycosylated hemoglobin $\left(\mathrm{HbA}_{1 \mathrm{c}}\right)>9 \%$ at the start of the observation period), hyperpotassemia $\left(5.5 \mathrm{mEq} \mathrm{ml}^{-1}\right)$ before the HD session, history of stroke, coronary heart disease, severe arrhythmia or any medical or surgical condition that may have affected the pharmacokinetics of the study drug and pregnant women.

\section{Study protocol}

The study was a 12-week multicenter study consisting of a 4-week observation period to fix dry weight and any drugs, including existing antihypertensives, and an 8-week treatment period with aliskiren. After the 4-week observation period, all eligible patients entered the 8-week treatment period during which they received aliskiren at $150 \mathrm{mg}$ orally in the morning once daily. BP was measured three times before all HD sessions. The reported BP was the average of all three measurements. Blood samples were obtained from arteriovenous shunt before HD sessions. PRA, angiotensin I (AT I), angiotensin II (AT II), aldosterone, BNP and hs-CRP were measured at baseline (week 0), and weeks 4 and 8 in the treatment period. $\mathrm{d}-\mathrm{ROM}$ was measured at baseline and at week 8 in the treatment period. The standard laboratory tests were performed in the observation period and at baseline, and weeks 4 and 8 in the treatment period. In addition, serum electrolytes (sodium, potassium, chloride) were measured at week 2.

\section{Laboratory methods}

PRA and aldosterone levels were determined by the radioimmunoassay method. AT I and AT II levels were measured by double antibody radioimmunoassay method; the details of these methods have been described elsewhere. ${ }^{10,11}$ The plasma level of BNP was measured by radioimmunoassay method. The plasma level of hs-CRP was measured by latex agglutination immunoassay methods. PRA, AT I, AT II, BNP, hs-CRP and other blood chemistry levels were determined by a clinical chemistry laboratory (Sanritsu,

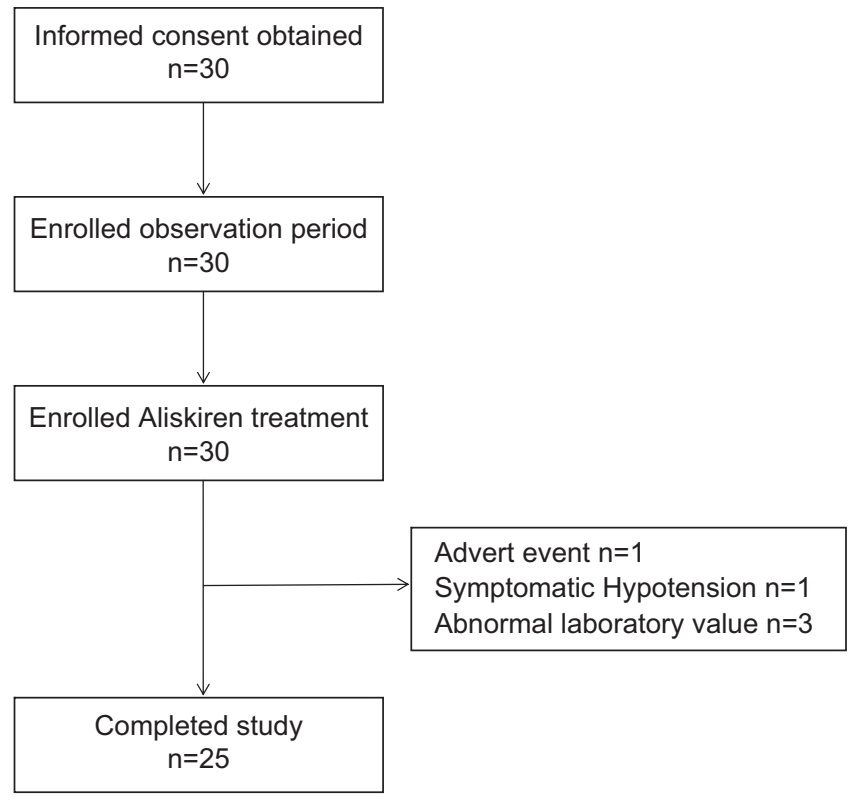

Figure 1 Patient flowchart.
Chiba, Japan). d-ROM values were measured using the Free carpe diem (Wismerll, Tokyo, Japan) the details of this method have been described elsewhere. ${ }^{12,13}$

\section{Statistical analysis}

All data are expressed as the mean \pm s.d. The paired Student's $t$-test or repeated measures analysis of variance was used to compare continuous data. Relationships between continuous variables were analyzed by Pearson's correlation tests. Differences with a $P$-value of $<0.05$ were considered significant.

\section{RESULTS}

A total of 30 patients entered the treatment period after the observation period (Figure 1). Of these 30 patients, 25 completed the study.

Table 1 Patient baseline characteristics $(n=25)$

\begin{tabular}{|c|c|c|}
\hline Parameter & Statistics & Standard value \\
\hline Age (years) & $68.0 \pm 8.6$ & \\
\hline \multicolumn{3}{|l|}{ Gender } \\
\hline Male & 16 & \\
\hline Female & 9 & \\
\hline $\mathrm{BMI}\left(\mathrm{kg} \mathrm{m}^{-2}\right)$ & $24.7 \pm 4.2$ & \\
\hline Time on dialysis (week) & $2.9 \pm 0.3$ & \\
\hline Duration of hemodialysis (years) & $6.8 \pm 7.5$ & \\
\hline \multicolumn{3}{|l|}{ Initial nephropathy } \\
\hline Chronic glomerulonephritis & 4 & \\
\hline Diabetic nephropathy & 14 & \\
\hline ANCA-associated glomerulonephritis & 1 & \\
\hline Drug nephropathy & 1 & \\
\hline Malignant hypertension & 1 & \\
\hline Unknown & 4 & \\
\hline SBP (mm Hg) & $169.0 \pm 20.1$ & \\
\hline DBP (mm Hg) & $78.1 \pm 12.0$ & \\
\hline HR (beats per min) & $83.2 \pm 11.2$ & \\
\hline \multicolumn{3}{|l|}{ PRA $\left(n g m r^{-1} h^{-1}\right)$} \\
\hline All $(n=25)$ & $3.6 \pm 4.0$ & $(0.2-2.7)$ \\
\hline ACEIs/ARBs $(-)(n=6)$ & $4.1 \pm 4.5$ & \\
\hline$(+)(n=19)$ & $2.5 \pm 2.2$ & \\
\hline \multicolumn{3}{|l|}{ AT $1\left(p g m r^{-1}\right)$} \\
\hline All & $1704.0 \pm 2580.9$ & $(\leqslant 500)$ \\
\hline ACEIs/ARBs (-) & $1257.1 \pm 1626.8$ & \\
\hline$(+)$ & $2653.7 \pm 3907.9$ & \\
\hline \multicolumn{3}{|l|}{ AT $2\left(p g \mathrm{ml}^{-1}\right)$} \\
\hline All & $70.2 \pm 121.5$ & $(\leqslant 22)$ \\
\hline ACEIs/ARBs (-) & $38.2 \pm 41.6$ & \\
\hline$(+)$ & $138.0 \pm 197.2$ & \\
\hline \multicolumn{3}{|l|}{ Ald $\left(p g m r^{-1}\right)$} \\
\hline All & $107.9 \pm 148.0$ & $(3-15)$ \\
\hline ACEIs/ARBs $(-)$ & $85.4 \pm 56.7$ & \\
\hline$(+)$ & $155.8 \pm 252.9$ & \\
\hline $\mathrm{BNP}\left(\mathrm{pg} \mathrm{ml^{-1 } )}\right.$ & $362.5 \pm 262.1$ & $(\leqslant 18.4)$ \\
\hline hs-CRP (mg l-1) & $6.2 \pm 8.1$ & $(\leqslant 0.6)$ \\
\hline d-ROM (U.CARR) & $367.0 \pm 89.8$ & $(250-300)$ \\
\hline
\end{tabular}

Abbreviations: ACEI, angiotensin I converting enzyme inhibitor; Ald, aldosterone; ANCA, antineutrophil cytoplasmic antibody; ARB, angiotensin receptor blocker; AT 1, angiotensin I: AT 2, angiotensin II; BMI, body mass index; BNP, brain natriuretic peptide; DBP, diastolic blood pressure; d-ROM, diacron-reactive oxygen metabolite; HR, heart rate; hs-CRP, high-sensitivity C-reactive protein; PRA, plasma renin activity; SBP, systolic blood pressure. 
Two discontinued treatment owing to an adverse event and symptomatic hypotension by aliskiren. The adverse event was eyebrow alopecia (1 patient). A possible connection to aliskiren treatment could not be excluded for the eyebrow alopecia. The symptomatic hypotension recovered to the basal level after aliskiren withdrawal. Increased serum potassium was not observed in any patients. Three patients were excluded from analysis because of abnormal laboratory values due to severe infectious diseases during the treatment period. Table 1 shows the characteristics of the study patients. Of the 25 patients, 23 had been taking antihypertensive drugs before the treatment period, including calcium antagonists (16 patients), ACEIs (6 patients), ARBs (18 patients), $\beta$-blockers (4 patients), $\alpha$-blockers (7 patients), $\alpha \beta$-blockers ( 4 patients) and $\alpha$-methyldopa (5 patients).

\section{Effect of aliskiren on BP}

Figure 2a shows that SBP ( \pm s.d) decreased from $169.0 \pm 20.1 \mathrm{~mm} \mathrm{Hg}$ at baseline to $162.9 \pm 21.2 \mathrm{~mm} \mathrm{Hg}$ at week 4 , followed by a further decrease to $153.7 \pm 19.6 \mathrm{~mm} \mathrm{Hg}$ at week $8(P<0.001)$. DBP ( \pm s.d) also decreased from $78.1 \pm 12.0 \mathrm{~mm} \mathrm{Hg}$ at baseline to $75.6 \pm 13.2 \mathrm{~mm} \mathrm{Hg}$ at week 4 , followed by a further decrease to $73.0 \pm 13.6 \mathrm{~mm} \mathrm{Hg}$ at week $8(P=0.048)$. Figure $2 \mathrm{~b}$ shows the BP change by aliskiren treatment in the group that received aliskiren combined with existing ACEIs and/or ARBs $(n=19)$ and the group for which the treatment was not combined with ACEI and/or ARBs $(n=6)$. The antihypertensive effect of aliskiren was comparable in the two groups.

\section{Blockade of RAAS by aliskiren}

Each factor of RAAS at week 0 in HDD-CKD patients was increased compared with the standard values (Table 1). PRA in the group that received ACEIs and/or ARBs was not higher than that in those not receiving these drugs. AT I, AT II and aldosterone in the group that received ACEIs and/or ARBs were higher than in those not receiving these drugs. The blockade effect of RAAS by aliskiren in all patients $(n=25)$ is shown in Figure 3a. PRA $( \pm$ s.d) decreased from $3.6 \pm 4.0 \mathrm{ng} \mathrm{ml}^{-1} \mathrm{~h}^{-1}$ at baseline to $1.2 \pm 1.7 \mathrm{ng} \mathrm{ml}^{-1} \mathrm{~h}^{-1}$ at week 4 , followed by a further decrease to $1.0 \pm 1.5 \mathrm{ng} \mathrm{m}^{-1} \mathrm{~h}^{-1}$ at week 8 $(P=0.004)$. AT I decreased from $1704.0 \pm 2580.9 \mathrm{pg} \mathrm{ml}^{-1}$ at baseline to $180.4 \pm 159.5 \mathrm{pg} \mathrm{ml}^{-1}$ at week 4 , followed by $233.7 \pm 181.0 \mathrm{pg} \mathrm{ml}^{-1}$ at week $8 \quad(P=0.009)$. AT II decreased from $70.2 \pm 121.5 \mathrm{pg} \mathrm{m}^{-1}$ at baseline to $13.0 \pm 10.2 \mathrm{pg} \mathrm{ml}^{-1}$ at week 4 to $12.4 \pm 11.5 \mathrm{pg} \mathrm{ml}^{-1}$ at week $8(P=0.022)$. Aldosterone decreased from $107.9 \pm 148.0 \mathrm{pg} \mathrm{ml}^{-1}$ at baseline to $67.4 \pm 39.0 \mathrm{pg} \mathrm{ml}^{-1}$ at week 4 to $73.1 \pm 34.6 \mathrm{pg} \mathrm{ml}^{-1}$ at week 8 (NS). Figure $3 \mathrm{~b}$ shows blockade effects of RAAS by aliskiren in the group receiving aliskiren combined with existing ACEIs and/or ARBs $(n=19)$, and the group for which the treatment was not combined with ACEI and/or ARBs $(n=6)$. Aliskiren inhibited RAAS in HDD-CKD patients regardless of the combination with ACEIs and/ or ARBs.

\section{Inhibition of BNP, HS-CRP and d-ROM by aliskiren}

BNP ( \pm s.d.) did not decrease $\left(362.5 \pm 262.1 \mathrm{pg} \mathrm{ml}^{-1}\right.$ at baseline to $362.6 \pm 278.2 \mathrm{pg} \mathrm{ml}^{-1}$ (NS)) at week 4 ; however, it significantly decreased to $300.0 \pm 232.0 \mathrm{pg} \mathrm{ml}^{-1}$ at week $8(P=0.043$; Figure 4). hs-CRP decreased from $6.2 \pm 8.1 \mathrm{mgl}^{-1}$ at baseline to $4.9 \pm 8.4 \mathrm{mgl}^{-1}$ at week 4 , followed by a further decrease to $3.5 \pm 3.7 \mathrm{mg} \mathrm{l}^{-1}$ at week $8(P=0.022)$ (Figure 4$)$. d-ROM significantly decreased from $367.0 \pm 89.8 \mathrm{U}$.CARR at baseline to $328.3 \pm 70.9 \mathrm{U}$.CARR at week 8 $(P=0.022$; Figure 4$)$. The extent of the decreases of BNP, hS-CRP and d-ROM did not correlate with reduced levels of SBP and DBP (Figure 5).

\section{DISCUSSION}

The results of this study show that aliskiren significantly decreased SBP and DBP in HDD-CKD patients. There are few studies that have evaluated the efficacy of a direct renin inhibitor (aliskiren) in
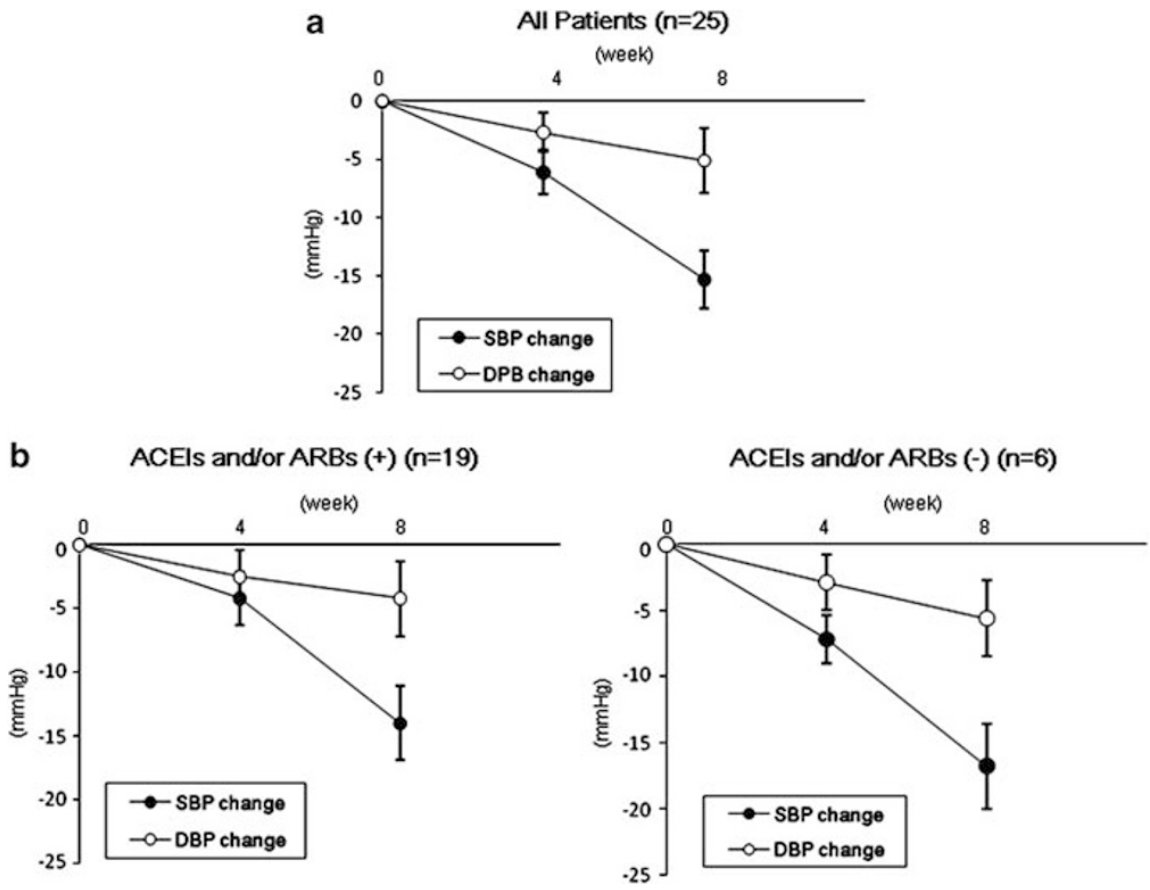

Figure 2 (a) Change in systolic blood pressure (SBP) and diastolic blood pressure (DBP) from baseline (week 0) to week 8. (b) The change in SBP and DBP from baseline to week 8 in the group in which aliskiren treatment was combined with angiotensin I converting enzyme inhibitors (ACEls) and angiotensin receptor blockers (ARBs), and the group in which it was not combined with ACEls and ARBs. 

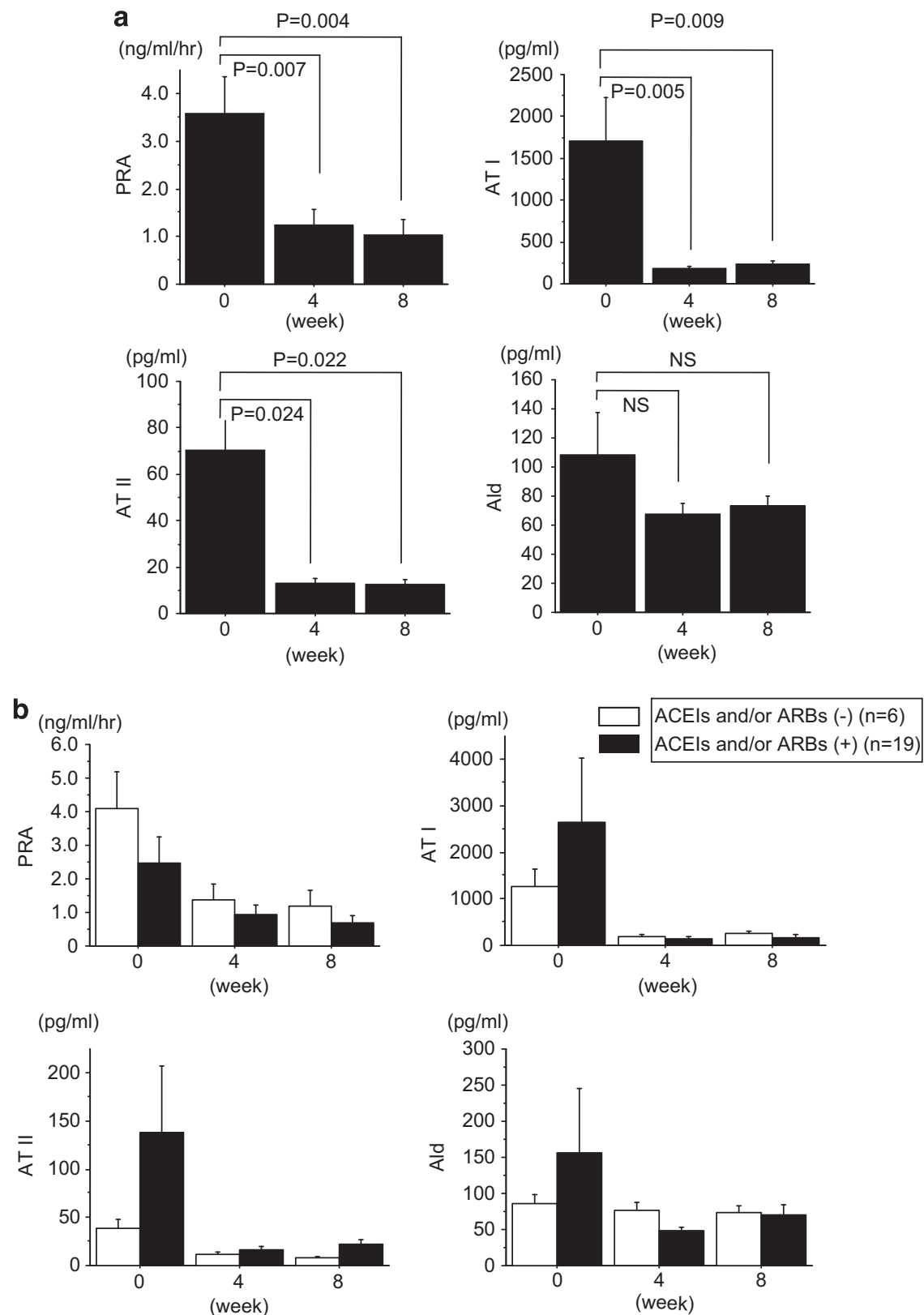

Figure 3 (a) Change in plasma renin activity (PRA), angiotensin I (AT I), angiotensin II (AT II) and aldosterone (Ald) by aliskiren treatment. (b) Change in PRA, AT I, AT II and Ald by aliskiren treatment in the group in which aliskiren treatment was combined with angiotensin I converting enzyme inhibitors (ACEIs) and angiotensin receptor blockers (ARBs), and the group in which it was not combined with ACEls and ARBs.

HDD-CKD patients with hypertension. ${ }^{14}$ This antihypertensive effect was comparable between the group that received ACEIs and/or ARBs and the group that did not receive ACEIs and/or ARBs. This result could be because of the fact that the dose of ACEIs and/or ARBs for HDD-CKD patients in this study was insufficient to block RAAS leading to BP control and cardiovascular protection because their hypertension was not controlled well and biomarkers for CVD did not decrease regardless of ACEI and/or ARB treatment. Although the sample number was small, the fact that ACEIs and/or ARBs did not lead to a reactive rise in PRA in the group that received ACEIs and/or ARBs also supports this possibility.

Activated RAAS has pivotal roles in developing CVD in HDD-CKD patients. ${ }^{15}$ Accumulated evidence has demonstrated that blockade of
RAAS not only prevents the progression, but also the regression of cardiovascular remodeling in HDD-CKD patients. ${ }^{8,16,17}$ In the present study, we evaluated BNP as a marker of heart function, predictably leading to CVD under aliskiren treatment because BNP reduction has consistently been associated with an improved outcome in heart failure. ${ }^{18-20}$ For instance, an increment of $10 \mathrm{pg} \mathrm{ml}^{-1}$ in BNP was associated with a $1.2 \%$ increased risk of death. ${ }^{18}$ Activated RAAS increased the inflammatory mediator that is an independent risk factor for CVD. ${ }^{4-6}$ Activated RAAS directly increases proinflammatory gene expression and activates oxidative stress, leading to progressive inflammation of the vascular endothelium. ${ }^{6}$ The elevated hs-CRP caused by persistent inflammation in uremic conditions has been shown to be an independent predictor of cardiovascular death in 

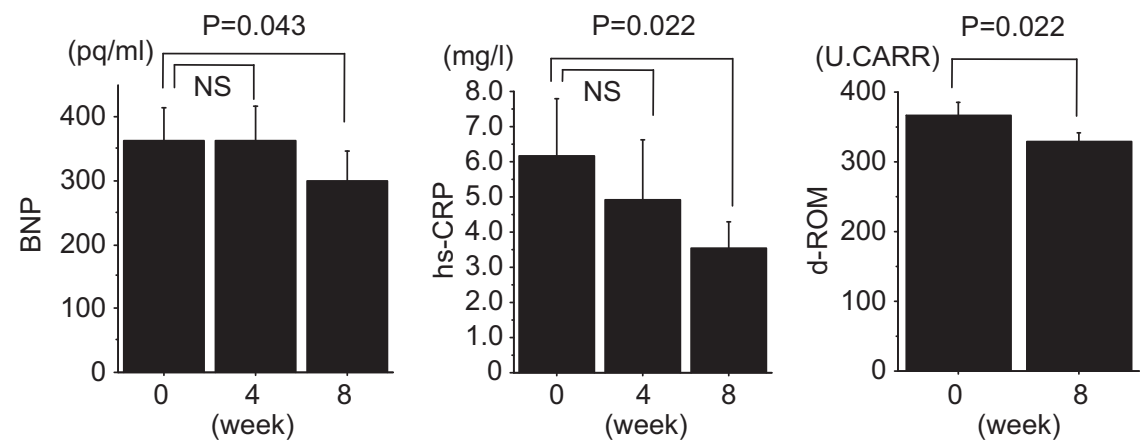

Figure 4 Change in brain natriuretic peptide (BNP), highly sensitive C-reactive protein (hs-CRP) and diacron-reactive oxygen metabolite (d-ROM) by aliskiren treatment.

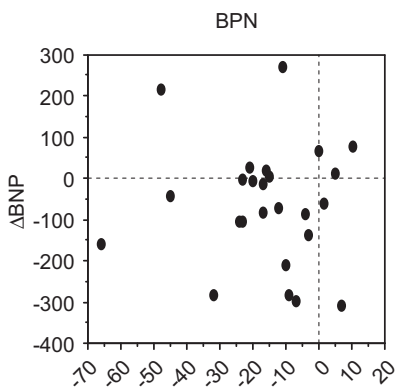

$\Delta \mathrm{SBP}$

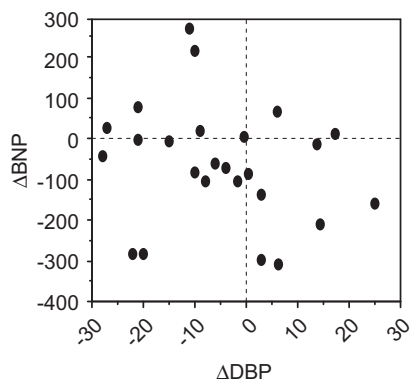

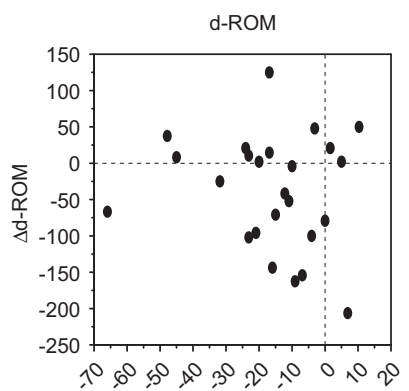

$\triangle \mathrm{SBP}$
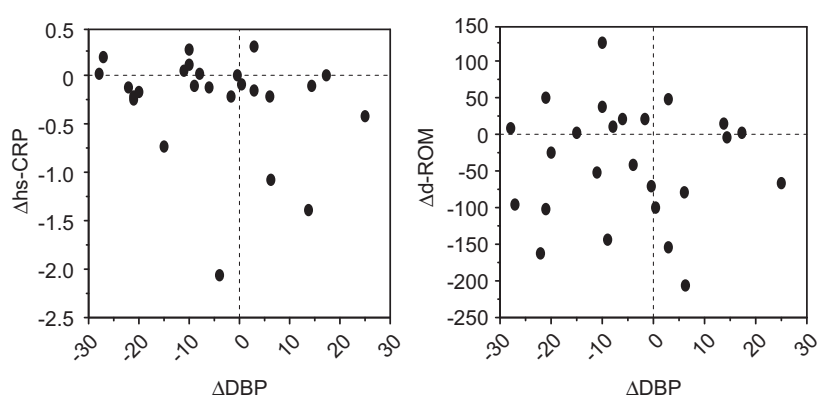

Figure 5 Correlation of the change in brain natriuretic peptide (BNP), highly sensitive C-reactive protein (hs-CRP) and diacron-reactive oxygen metabolite (d-ROM), and the change in SBP $(\triangle \mathrm{SBP})$ and $\mathrm{DBP}(\triangle \mathrm{DBP})$ by aliskiren treatment.

HDD-CKD patients. ${ }^{4,5}$ The d-ROM level represents the total level of peroxidized metabolites. $\mathrm{d}-\mathrm{ROM}$ has been used to evaluate the oxidative status, and its significance as a clinical marker has been reported in various fields, including HDD-CKD patients. ${ }^{12,13}$ Therefore, we evaluated the change of hs-CRP as an inflammation marker and d-ROM as an oxidative stress marker by aliskiren treatment. In the present study, BNP, hs-CRP and d-ROM were significantly decreased by aliskiren treatment. These results suggest that aliskiren could decrease cardiovascular events in HDD-CKD patients. Previous studies reported that aliskiren has a cardiovascular protective effect. Left Ventricular Assessment of Hypertrophy (ALLAY) study demonstrated that aliskiren reduced left ventricular hypertrophy in hypertensive patients. ${ }^{21}$ Moreover, several studies demonstrated that the cardiovascular protective effect of aliskiren was independent of BPlowering effect. The Aliskiren Observation of Heart Failure Treatment (ALOFT) study demonstrated that aliskiren decreased BNP in heart failure patients not by a BP-lowering effect but possibly by increased natriuresis. ${ }^{22}$ Westermann et al. ${ }^{23}$ reported that aliskiren improved cardiac function and remodeling after myocardial infarction by normalization of intracellular signaling stimulated by AT II without altering BP in an animal model. Imanishi et al. ${ }^{24}$ reported that aliskiren improved vascular endothelial function and protected against atherosclerosis by impaired nitric oxide bioavailability and decreased inflammatory mediators without altering BP in an animal model. In this study, the decreased levels of BNP, hs-CRP and d-ROM by aliskiren treatment did not correlate with the decreased levels of SBP and DBP. These results suggested that aliskiren may have cardiovascular protective effects not only by an antihypertensive effect but also by a non-antihypertensive effect in HDD-CKD patients with hypertension. In this study, aliskiren may have decreased biomarkers for CVD by improving intracellular signaling and vascular endothelial function by decreasing inflammatory mediators but not by increasing natriuresis in addition to a BP-lowering effect because all enrolled patients had oliguria or anuria. Further studies will need to investigate the mechanism of cardiovascular protective effects by aliskiren in HDD-CKD patients with hypertension 
Several studies reported that mean trough plasma aliskiren concentrations increased by renal impairment; ${ }^{25,26}$ however, an increase in exposure does not correlate with the severity of renal impairment. ${ }^{25}$ Moreover, renal clearance of aliskiren represents only a small fraction (0.1-1.0\%). ${ }^{9}$ These data suggest that adjustment of the aliskiren dose is unlikely to be required in HD patients. Further studies will be required to investigate the pharmacokinetics of aliskiren in HD patients.

In conclusion, aliskiren was effective for BP control and has cardiovascular protective effects in hypertensive HDD-CKD patients.

1 Blankestijn PJ, Ligtenberg G. Volume-independent mechanisms of hypertension in hemodialysis patients: clinical implications. Semin Dial 2004; 17: 265-269.

2 Weidmann P, Maxwell MH, Lupu AN, Lewin AJ, Massry SG. Plasma renin activity and blood pressure in terminal renal failure. N Engl J Med 1971; 285: 757-762.

3 Mimran A, Shaldon S, Barjon P, Mion C. The effect of an angiotensin antagonist (saralasin) on arterial pressure and plasma aldosterone in hemodialysis-resistant hypertensive patients. Clin Nephrol 1978; 9: 63-67.

4 Racki S, Zaputovic L, Mavric Z, Vujicic B, Dvornik S. C-reactive protein is a strong predictor of mortality in hemodialysis patients. Ren Fail 2006; 28: 427-433.

5 Zoccali C, Benedetto FA, Mallamaci F, Tripepi G, Fermo I, Foca A, Paroni R, Malatino LS. Inflammation is associated with carotid atherosclerosis in dialysis patients. Creed Investigators. Cardiovascular Risk Extended Evaluation in Dialysis Patients. J Hypertens 2000; 18: 1207-1213.

6 Landomesser $\mathrm{U}$, Drexler $\mathrm{H}$. Oxidative stress, the renin-angiotensin system, and atherosclerosis. Eur Heart J 2003; 5: A3-A7.

7 Argani H, Ghorbanihaghjo A, Aghaeishahsavari M, Noroozianavval M, Rashtchizadeh N, Veisi P, Safa J, Abediazar S. Effects of losartan and enalapril on high-sensitivity Creactive protein and total antioxidant in renal transplant recipients with renin-angiotensin system polymorphisms. Transplant Proc 2008; 40: 16-21.

8 Suzuki H, Kanno Y, Sugahara S, Ikeda N, Shoda J, Takenaka T, Inoue T, Araki R. Effect of angiotensin receptor blockers on cardiovascular events in patients undergoing hemodialysis: an open-label randomized controlled trial. Am J Kidney Dis 2008; 52: 501-506.

9 Nussberger J, Wuerzner G, Jensen C, Brunner HR. Angiotensin II suppression in humans by the orally active renin inhibitor Aliskiren (SPP100): comparison with enalapril. Hypertension 2002; 39: E1-E8.

10 Rodbard D. Statistical quality control and routine data processing for radioimmunoassays and immunoradiometric assays. Clin Chem 1974; 20: 1255-1270.

11 Emanuel RL, Cain JP, Williams GH. Double antibody radioimmunoassay of renin activity and angiotensin II in human peripheral plasma. J Lab Clin Med 1973; 81: $632-640$
12 Cesarone MR, Belcaro G, Carratelli M, Cornelli U, De Sanctis MT, Incandela L, Barsotti A, Terranova R, Nicolaides A. A simple test to monitor oxidative stress. Int Angiol 1999; 18: 127-130.

13 Gerardi G, Usberti M, Martini G, Albertini A, Sugherini L, Pompella A, Di LD. Plasma total antioxidant capacity in hemodialyzed patients and its relationships to other biomarkers of oxidative stress and lipid peroxidation. Clin Chem Lab Med 2002; 40: 104-110.

14 Rubin J. Aliskiren for hypertension control in chronic dialysis patients. J Am SoC Nephrol 2009; 20: 844A.

15 Laragh JH. Renin profiling for diagnosis, risk assessment, and treatment of hypertension. Kidney Int 1993; 44: 1163-1175.

16 Shibasaki Y, Nishiue T, Masaki H, Matsubara H, Iwasaka T. Angiotensin II type 1 antagonist suppress left ventricular hypertrophy and myocardial fibrosis in patient with end stage renal disease (ESRD)]. Nippon Rinsho 2002; 60: 1992-1998.

17 Ruiz-Ortega M, Ruperez M, Esteban V, Rodriguez-Vita J, Sanchez-Lopez E, Carvajal G, Egido J. Angiotensin II: a key factor in the inflammatory and fibrotic response in kidney diseases. Nephrol Dial Transplant 2006; 21: 16-20.

18 Latini R, Masson S, Anand I, Salio M, Hester A, Judd D, Barlera S, Maggioni AP, Tognoni G, Cohn JN. The comparative prognostic value of plasma neurohormones at baseline in patients with heart failure enrolled in Val-HeFT. Eur Heart J 2004; 25: 292-299.

19 Latini R, Masson S, Wong M, Barlera S, Carretta E, Staszewsky L, Vago T, Maggioni AP, Anand IS, Tan LB, Tognoni G, Cohn JN. Incremental prognostic value of changes in Btype natriuretic peptide in heart failure. Am J Med 2006; 119: 70.e23-70.e30.

20 Jourdain P, Jondeau G, Funck F, Gueffet P, Le Helloco A, Donal E, Aupetit JF, Aumont MC, Galinier M, Eicher JC, Cohen-Solal A, Juilliere Y. Plasma brain natriuretic peptideguided therapy to improve outcome in heart failure: the STARS-BNP Multicenter Study. J Am Coll Cardiol 2007; 49: 1733-1739.

21 Solomon SD, Appelbaum E, Manning WJ, Verma A, Berglund T, Lukashevich V, Cherif Papst C, Smith BA, Dahlof B. Effect of the direct Renin inhibitor aliskiren, the Angiotensin receptor blocker losartan, or both on left ventricular mass in patients with hypertension and left ventricular hypertrophy. Circulation 2009; 119: 530-537.

22 McMurray JJ, Pitt B, Latini R, Maggioni AP, Solomon SD, Keefe DL, Ford J, Verma A, Lewsey J. Effects of the oral direct renin inhibitor aliskiren in patients with symptomatic heart failure. Circ Heart Fail 2008; 1: 17-24.

23 Westermann D, Riad A, Lettau O, Roks A, Savvatis K, Becher PM, Escher F, Jan Danser $\mathrm{AH}$, Schultheiss HP, Tschope C. Renin inhibition improves cardiac function and remodeling after myocardial infarction independent of blood pressure. Hypertension 2008; 52: 1068-1075.

24 Imanishi T, Tsujioka H, Ikejima H, Kuroi A, Takarada S, Kitabata H, Tanimoto $T$, Muragaki Y, Mochizuki S, Goto M, Yoshida K, Akasaka T. Renin inhibitor aliskiren improves impaired nitric oxide bioavailability and protects against atherosclerotic changes. Hypertension 2008; 52: 563-572.

25 Vaidyanathan S, Bigler H, Yeh C, Bizot MN, Dieterich HA, Howard D, Dole WP. Pharmacokinetics of the oral direct renin inhibitor aliskiren alone and in combination with irbesartan in renal impairment. Clin Pharmacokinet 2007; 46: 661-675.

26 Ito S, Nakura N, Le Breton S, Keefe D. Efficacy and safety of aliskiren in Japanese hypertensive patients with renal dysfunction. Hypertens Res 2010; 33: 62-66. 